\title{
Os conhecimentos tradicionais dos(as) erveiros(as) da Feira do Ver-o-Peso (Belém, Pará, Brasil): um olhar sob a ótica da Ciência da Informação
}

\section{Cleide Furtado Nascimento Dantas}

Bacharela em Biblioteconomia (UFPA), discente do Curso de Especialização em Gestão e Docência na Educação Superior (UNAMA) e Bibliotecária da Secretaria Municipal de Meio Ambiente (SEMMA) de Belém

Rubens da Silva Ferreira

Bacharel em Biblioteconomia (UFPA), Especialista em Biblioteca Universitária (UFPA), Mestre em Planejamento do Desenvolvimento Regional (NAEA/UFPA), doutorando do PPGCI/IBICT-UFRJ e docente da Faculdade de Biblioteconomia (FABIB/ICSA/UFPA)

Estudo sobre os conhecimentos tradicionais detidos pelos(as) erveiros(as) da Feira Livre do Ver-o-Peso, em Belém, Pará, Brasil. Em termos gerais, busca-se contribuir com o tema, na perspectiva da Ciência da Informação. Do ponto de vista da investigação, utiliza a pesquisa bibliográfica e etnográfica, em direção à compreensão dos processos de aquisição, armazenamento e transferência de informações sobre plantas, cascas e raízes medicinais comercializadas pelos atores em foco. Verifica que a aquisição e a transmissão desse saber se dá pela observação e pela oralidade no contato cotidiano do trabalho com esses produtos, seguindo armazenado apenas na memória de seus detentores. Por fim, aponta os riscos que permeiam os conhecimentos tradicionais dos(as) erveiros(as) da Feira do Ver-o-Peso e as possibilidades que o tema oferece à Ciência da Informação.

Palavras-chave: Informação; Conhecimentos tradicionais; Feira do Ver-o-Peso - Belém (PA/Brasil). 


\section{The traditional knowledge of herb sellers of the Ver-o-Peso Fair (Belém, Pará, Brazil): a look under the optics of the Information Science}

Study about the traditional knowledge gotten by the herb sellers of the Ver-o-Peso free market, in Belém, Pará, Brazil. On the whole, it aims to contribute with the theme in the perspective of the Information Science. From the point of view of the investigation, it uses the bibliographic and ethnographic research towards the comprehension of the process of acquisition, warehousing and transference of the information about plants, peels and medicinal roots traded by the authors in focus. It verifies that the acquisition and the transmission of this knowledge occurs by the observation and by the orality in the day-to-day contact of the work with those products, kept only in the memory of the owners. Finally, this study shows the risks that permeate the traditional knowledge of the herb sellers of the Ver-o-Peso free market and the possibilities that the theme offers to the Information Science.

keywords: Information; Traditional knowledge; Ver-oPeso Fair - Belém (PA/Brasil).

Recebido em 29.04.2012 Aceito em 06.03.2013

\section{Introdução}

Dotado do pensamento complexo, o Homo sapiens distingue-se de outras categorias de seres vivos por sua capacidade de produzir informações sobre o meio que, ao serem convertidas em conhecimento por determinados processos mentais, destinam-se a orientar as ações humanas no mundo. Isto é, produzir sentido sobre o que se observa, ouve e sente e, após o aparecimento da escrita a 3.500 anos A.C., sobre o que se lê. É a natureza da informação assimilada do meio pelo homem que irá determinar o tipo de conhecimento a ser mentalmente construído. Assim, do ponto de vista didático, os manuais de ciência costumam distinguir as modalidades de conhecimento em comum, religioso, filosófico e científico, porém, sem dedicar atenção ao chamado conhecimento tradicional.

Desse modo, o interesse em realizar um estudo sobre os conhecimentos detidos por populações tradicionais partiu de uma reflexão sobre como eles podem ser pensados à luz da Ciência da Informação. Ou seja, como compreendê-los do ponto de vista de uma ciência de caráter 
interdisciplinar, dedicada ao estudo dos processos sociais de criação, armazenamento, transferência e uso de informações, que se desenvolveu nos anos de 1960 do século passado, mas para dar conta do conhecimento científico e tecnológico (PINHEIRO; LOUREIRO, 1995). E, ao trazer o tema para o diálogo com Saracevic (1995), verifica-se que a Ciência da Informação também pode ser entendida como aquela delineada em torno dos problemas relacionados à comunicação do conhecimento humano na perspectiva individual, social e institucional, ampliando, desse modo, suas possibilidades de análise.

Quanto aos estudos existentes sobre os conhecimentos tradicionais em sua problemática contemporânea, a literatura revela uma produção maior no campo da Antropologia, da Sociologia e do Direito. No entanto, o tema carece de investigações no âmbito da Ciência da Informação, a qual toma por objeto de estudo a matéria-prima que permite a construção de todo tipo de conhecimento ${ }^{1}$. Com efeito, essa lacuna serve de mote para a elaboração deste trabalho focado nos conhecimentos tradicionais dos(as) erveiros(as) da Feira do Ver-o-Peso na cidade de Belém (PA/Brasil).

O objetivo geral da pesquisa consistiu em entender como esses atores adquirem e transmitem um tipo de saber aplicado à cura dos males do corpo e da alma, dentro do que se entende como medicina popular ${ }^{2}$. No plano específico, procurou-se identificar os riscos que se impõem aos/às erveiros(as) da feira em questão, precipuamente no que se refere aos interesses econômicos de exploração dos conhecimentos tradicionais, sem levar em consideração a repartição dos benefícios. Também, buscouse verificar como esses atores veem a continuidade desse saber especializado, do ponto de vista geracional. Por trás desses objetivos, o que se tem é um esforço de olhar a informação sob a ótica da aquisição, da transmissão, do processamento, da recuperação e do uso, mas na vida cotidiana, procurando fugir a uma tradição acadêmica que tem privilegiado esses processos no campo científico e tecnológico. Ou, ainda, mediado quase que exclusivamente pelas Tecnologias de Informação e Comunicação (TIC), em detrimento ao componente mais importante de todo o processo informacional: o homem.

Diante do contexto apresentado, na sequência a esta introdução, tem-se uma discussão teórica sobre informação, conhecimento e conhecimentos tradicionais. Em seguida, faz-se a exposição do desenho metodológico adotado na produção das evidências. Nas considerações finais, destaca-se a necessidade de aprofundamento do tema no campo da Ciência da Informação, sobretudo em função do objeto de estudo em torno do qual ela está delineada. Aponta, também, para a necessidade da presença maior do Estado na proteção dos saberes tradicionais, que ainda

\footnotetext{
1 Uma das poucas contribuições nesta direção é o trabalho de Souza e Carvalho (2007), que se dedicaram ao estudo dos processos de disseminação da informação sobre plantas medicinais nas feiras livres da capital soteropolitana.

2 Também chamada medicina folk, tida como o conjunto de práticas e crenças "rústicas" e "imitativas" que surgiram em função da fusão e da difusão de saberes curativos, relacionados às diferentes etnias que formam uma determinada sociedade (ARAúJO, 1959).
} 
encontram sua aplicação na vida moderna, quer em áreas rurais ou urbanas do país.

\section{Entendendo os termos centrais da pesquisa: informação, conhecimento e conhecimentos tradicionais}

Realizar uma pesquisa sobre os conhecimentos tradicionais dos(as) erveiros(as) da Feira do Ver-o-Peso implicou no entendimento de três termos essenciais: informação; conhecimento; e conhecimentos tradicionais. De acordo com McGarry (1999), apesar da popularidade da palavra informação nos dias atuais, foi a partir do século $X V$, após a invenção da imprensa, que ela começou a se disseminar na sociedade ocidental para então adquirir sentido plural na contemporaneidade (McGARRY, 1999). Empregada em vários contextos, ela é sinônimo de fato; reforço do que já se conhece; dado dotado de sentido; conteúdo mediado na comunicação; conhecimento aplicado à ação; ou elemento redutor de incertezas diante de uma determinada situação (WERSIG; NEVELING, 1975; BRAGA, 1995; McGARRY, 1999). Para a Ciência da Informação, entre outras possibilidades, ela pode ser utilizada no sentido proposto por Le Coadic (2004, p. 4), ou seja, como "[...] um conhecimento inscrito (registrado) em forma escrita (impressa ou digital), oral ou audiovisual, em um suporte [...]". Entretanto, há que se considerar que nem toda a informação existente no mundo se encontra registrada, e ao se pensar assim, incorre-se no risco de considerar todo(s) $\mathrm{o}(\mathrm{s})$ indivíduo(s) pertencente(s) a sociedades ou comunidades ágrafas como pessoa(s) desinformada(s). E, de igual modo, enquadrar todo 0 indivíduo não alfabetizado de sociedades complexas como aquele que não participa de processos informacionais simples, tal como é o caso da comunicação oral nas interações sociais do dia a dia.

Destarte, nesta pesquisa, prefere-se entender a informação pela contribuição de Belkin e de Robertson (1976), que a vislumbram como elemento transformador de estruturas. Tal proposição ajuda a analisá-la como estímulo externo capaz de modificar o estado de consciência do homem, levando-o a conhecer algo até então desconhecido. Aliás, verifica-se que frequentemente a palavra informação aparece associada ao conhecimento e vice-versa. A exemplo, tem-se as definições encontradas em diferentes dicionários, como no Concise Oxford dictionary of current English, em que o termo figura como "information $n$. informing, telling; thing told, knowledge, (desired) items of knowledge, news; [...]" (McGARRY, 1999, p. 2). A mesma situação ocorre no Dicionário de Biblioteconomia e Arquivologia, no qual informação figura como o "[...] Registro de um conhecimento que pode ser necessário a uma decisão [...]. [e] Registro de um conhecimento para utilização posterior [...]" (CUNHA; CAVALCANTI, 2008, p. 201).

Seja como for, o fato é que há uma relação de interdependência entre informação e conhecimento, pois ela é tida como a matéria-prima que continuamente alimenta a geração de novos saberes (BARBOSA, 
1997; McGARRY, 1999). De acordo com Barros e Lehfeld (2007, p. 38), "[...] o conhecimento é o resultado de um processo histórico", pelo qual as experiências do meio em que se vive afetam diretamente no modo de agir do homem, no relacionamento com a natureza e na maneira de pensar. Por isso, ele nasce a partir das informações acumuladas na vida cotidiana, quer em contextos formais ou informais, bem como das interações sociais e das leituras de mundo que os indivíduos são capazes de realizar (TEIXEIRA, 2005), independente de serem alfabetizados ou não.

No que diz respeito aos conhecimentos tradicionais, embora existam definições propostas por diferentes autores, elas convergem ao menos em alguns pontos. O mais importante deles é o princípio de que se trata de um conjunto de saberes constituído pela experiência, fruto do contato entre povos, grupos humanos ou indivíduos - sejam eles indígenas, afrodescendentes, comunidades rurais e outros - com a natureza, sendo transmitidos de pai para filho e, geralmente, de forma oral. Na atualidade, esse tipo de conhecimento vem sendo utilizado como estratégia de redução do tempo nas pesquisas realizadas pela indústria farmacêutica, mesmo que nem sempre sejam obtidas as devidas autorizações; ou, ainda, sem a repartição dos benefícios junto aos detentores desses saberes ${ }^{3}$. Essa prática abusiva gera, então, um campo de tensão quanto a quem cabe a propriedade desses conhecimentos, o que se coloca como um problema a ser enfrentado pelas populações tradicionais ${ }^{4}$ de diferentes países, entre eles o Brasil.

Os conhecimentos tradicionais podem ser definidos como o legado de um antepassado ancestral, ou seja, como conhecimentos coletivos ou individuais, adquiridos por comunidades tradicionais de acordo com seus hábitos e práticas culturais que se relacionam com o meio ambiente. Em outros termos, é dizer que:

El conocimiento tradicional sería el conjunto de sabidurías y la adopción de tecnologías desarrolladas particular y colectivamente, fundadas en las experiencias ancestrales transmitidas, preservadas, innovadas y practicadas por un pueblo indígena o comunidades locales (BARROS et al., 2007, p. 26).

3 Os(as) erveiros(as) do Ver-o-Peso já foram alvo de ações desse tipo em 2001, o que envolveu a empresa de cosméticos Natura. Tal como relatado por Lima (2008), em dissertação de mestrado, o episódio teve início quando pessoas que se identificaram como repórteres dessa empresa se dirigiram ao setor de ervas da Feira do Ver-o-Peso. Acreditando que a reportagem iria resultar no incremento das vendas, os(as) erveiros(as) forneceram várias informações sobre os produtos que comercializam, inclusive sobre a priprioca (Cyperus articulatus L.). A partir das informações coletadas, a Natura começou a produzir perfumes sem o consentimento dos(as) erveiros(as), que, ao se sentirem lesados, acionaram o Ministério Público Estadual, resultando em ação que culminou num acordo entre as partes.

4 Tal como observa Kishi (2006, não paginado), do ponto de vista legal existem discordâncias quanto aos sujeitos que podem ser incluídos no conceito de populações tradicionais. Assim, a partir da Lei do Sistema Nacional de Unidades de Conservação (Lei no 9.985, de 18/07/2000) esse autor defende que as populações tradicionais sejam entendidas como aquelas cuja existência está assentada "em sistemas sustentáveis de exploração dos recursos naturais, desenvolvidos ao longo de gerações e adaptados às condições ecológicas locais e que desempenham um papel fundamental na proteção da natureza e na manutenção da diversidade biológica". 
Neste ponto, há, na literatura, uma concordância de que esse tipo de conhecimento foi construído no decorrer da história de diferentes povos, portanto, não sendo formado de uma hora para outra. Isso pode ser evidenciado, por exemplo, em Santos ([20--?]), ao afirmar que o conhecimento tradicional está relacionado às práticas, aos conhecimentos empíricos, aos costumes e às crenças dessas comunidades. Dessa maneira, configura-se como o resultado de um processo histórico, social e cultural de acumulação de informações e de conhecimentos por seus detentores ao longo do movimento das sucessivas gerações no tempo e no espaço.

No cenário econômico mundial contemporâneo, verifica-se que os conhecimentos tradicionais têm despertado o interesse de segmentos industriais e empresariais baseados na utilização dos recursos genéticos e do saber a eles associados. Na opinião de Moreira (2007, p. 34):

Esses conhecimentos, que até então se destinavam à manutenção das formas de vida das sociedades tradicionais, a partir do século XX passam a ser vistos sob uma ótica utilitarista decorrente do novo cenário científico e tecnológico que se delineia e que ganha contornos claros com a ascensão de novas tecnologias as quais passam a identificar nesses recursos um forte potencial industrial.

Com isso, assiste-se a uma preocupação global crescente quanto à necessidade de proteção não somente desses conhecimentos como, também, dos interesses dos sujeitos que os detêm, o que tem trazido a discussão à baila inclusive no Brasil.

Conforme se observa em Santos (2006), há um propósito muito claro dos grupos industriais quanto aos conhecimentos tradicionais. Para esse autor:

O que se quer é acessar as propriedades das plantas, animais, etc. através do conhecimento tradicional para produzir pequenas alterações que serão escritas em linguagem tecnocientífica, e obter então uma patente específica baseada nessas pequenas modificações, afetando, entretanto, aquilo que o conhecimento tradicional descobriu (SANTOS, 2006, não paginado).

É diante dessa realidade que se evidencia o desequilíbrio e a contradição existente entre o valor conferido pelas sociedades ocidentais capitalistas ao conhecimento científico e tecnológico e o valor que se atribui aos conhecimentos tradicionais, uma vez que agentes industriais e empresariais têm se utilizado deste segundo para ampliar os investimentos e, consequentemente, obter mais lucro.

No panorama em que se alinham as forças entre exploradores e explorados, isto é, industriais, empresários e investidores de um lado e populações tradicionais do outro, Santilli (2005, p. 77) defende que: 
[...] as políticas públicas devem promover um tratamento equitativo da ciência ocidental e do saber tradicional, reconhecendo que os sistemas tradicionais de conhecimentos têm os próprios fundamentos científicos e epistemológicos. 0 conhecimento tradicional não é estático, e sim dinâmico, e o termo "tradicional" não se refere à sua antiguidade: não se trata apenas de conhecimentos "antigos", ou "passados", mas conhecimentos também presentes e futuros que evoluem e se transformam, com base em práticas dinâmicas.

Como se vê, os discursos dos grupos de interesse, que valorizam o conhecimento científico, acabam por sociodesvalorizar os detentores dos conhecimentos tradicionais, o que contribui para a apropriação industrial indevida deste último, principalmente, pelos produtores de fármacos e de cosméticos. Todavia, os saberes fundamentados na tradição estão de acordo com o estilo de vida das sociedades, das comunidades, dos grupos e/ou dos indivíduos que os possuem, e por isso não devem ser entendidos como inferiores (LARAIA, 2009). E, uma vez entendidos os termos essenciais desta pesquisa, a parte seguinte é dedicada à apresentação da metodologia utilizada.

\section{0 desenho metodológico da pesquisa junto aos/às erveiros(as) da Feira do Ver-o-Peso}

Em sua condução, o estudo foi dedicado, em sua primeira fase, à realização da pesquisa bibliográfica, a fim de localizar fontes diversas produzidas sobre informação, conhecimento e conhecimentos tradicionais. É este primeiro passo que permite a construção dos entendimentos preliminares sobre aquilo que se está investigando, o que o coloca como procedimento inicial e obrigatório em qualquer empreendimento científico (ECO, 2007). Nesta direção, Barros et al. (2007), McGarry (1999), Moreira (2007), Lima (2008) e outros são tomados em sua produção teórica para a geração de entendimentos sobre a realidade que se quis estudar.

Ao escolher investigar os conhecimentos tradicionais dos(as) erveiros(as) do Ver-o-Peso pelo olhar da Ciência da Informação, a pesquisa foi desenhada para seguir a abordagem qualitativa. Em expansão contínua e utilizada desde a década de 1970 do século passado, de acordo com Appolinário (2007), neste tipo de enfoque a coleta de dados se dá por meio de interações sociais, a exemplo dos estudos etnográficos e das pesquisas participantes, sendo analisados de forma subjetiva pelo pesquisador. Entre outras coisas, ela é caracterizada por ser interpretativa e descritiva, ou seja, "[...] se propõe a estudar relações complexas, sem o isolamento de variáveis buscando, compreender e interpretar o fenômeno em seu contexto natural [...]" (OLIVEIRA, 2008, p. 100). E, quando se fala em fenômeno, há que se chamar a atenção para o pesquisador/observador, sujeito que desempenha papel seminal na interpretação da realidade investigada (APPOLINÁRIO, 2007), por meio das evidências que é capaz de obter no trabalho de campo. 
Com relação ao tipo de pesquisa, utilizou-se a etnográfica, a fim de verificar entre os(as) erveiros(as) como se dá a construção dos conhecimentos que possuem sobre ervas, cascas e raízes medicinais. Conforme Appolinário (2007, p. 87), a etnografia corresponde àquela que objetiva "[...] descrever e analisar as práticas, crenças e valores culturais de uma comunidade [...]". Ou, como explicam Sousa e Barroso (2008, p. 151), na investigação etnográfica o pesquisador procura "[...] estabelecer relações, selecionar informantes e tentar salvar o dito em um discurso social em formas pesquisáveis [...]". Desse modo, levantar as evidências sobre os conhecimentos tradicionais dos(as) erveiros(as) implicou em deslocamentos até o local onde esses sujeitos trabalham diariamente, a fim de perguntar, ouvir, observar, anotar, gravar e fotografar tudo o que pudesse interessar à pesquisa, mas respeitando os princípio éticos. ${ }^{5}$

O locus da pesquisa foi a Feira do Ver-o-Peso, que surgiu no século XVII, como um entreposto comercial e como posto de arrecadação fiscal (MENEZES, 1993), expandindo-se em meio à movimentação e à comercialização de produtos diversos, provenientes tanto do estado do Pará quanto do restante do Brasil e do mercado internacional, principalmente da Europa. Ela foi implantada na confluência dos dois primeiros bairros de Belém, a Cidade Velha e a Campina, precisamente na Doca de Embarcações, onde "[...] eram pesadas as mercadorias embarcadas, taxadas pelo peso, e os impostos recolhidos para a Câmara de Belém" (LIMA, 2008, p. 37). A partir da sua extinção como posto fiscal, o Ver-o-Peso passou à condição de centro de abastecimento de Belém e ponto turístico dos mais visitados. Nesse espaço, existe o conhecido setor de ervas medicinais, bastante procurado pela população local e pelos turistas. Atualmente, o setor está localizado entre o prédio do Mercado de Peixe e do Solar da Beira, os quais integram o Complexo do Ver-o-Peso. Em sua estrutura, esse setor é constituído por 80 barracas, 50 delas gerenciadas por erveiras e 30 por erveiros. O espaço está fixado entre a Baia do Guajará e a Avenida Boulevard Castilho França. Quanto à organização, as barracas estão distribuídas em quatro filas de duas em duas, unidas pelos fundos (LIMA, 2008), sendo que uma parte delas pode ser vista na Figura 1.

Para atender a esse princípio, foi elaborado um Termo de Autorização de Imagem e Entrevista, assinado por todos os informantes contatados nessa feira livre de Belém, o que se deu após terem sido esclarecidos quanto à natureza e à finalidade da pesquisa. 
Figura 1 - Vista parcial das barracas dos(as) erveiros(as) do Ver-o-Peso

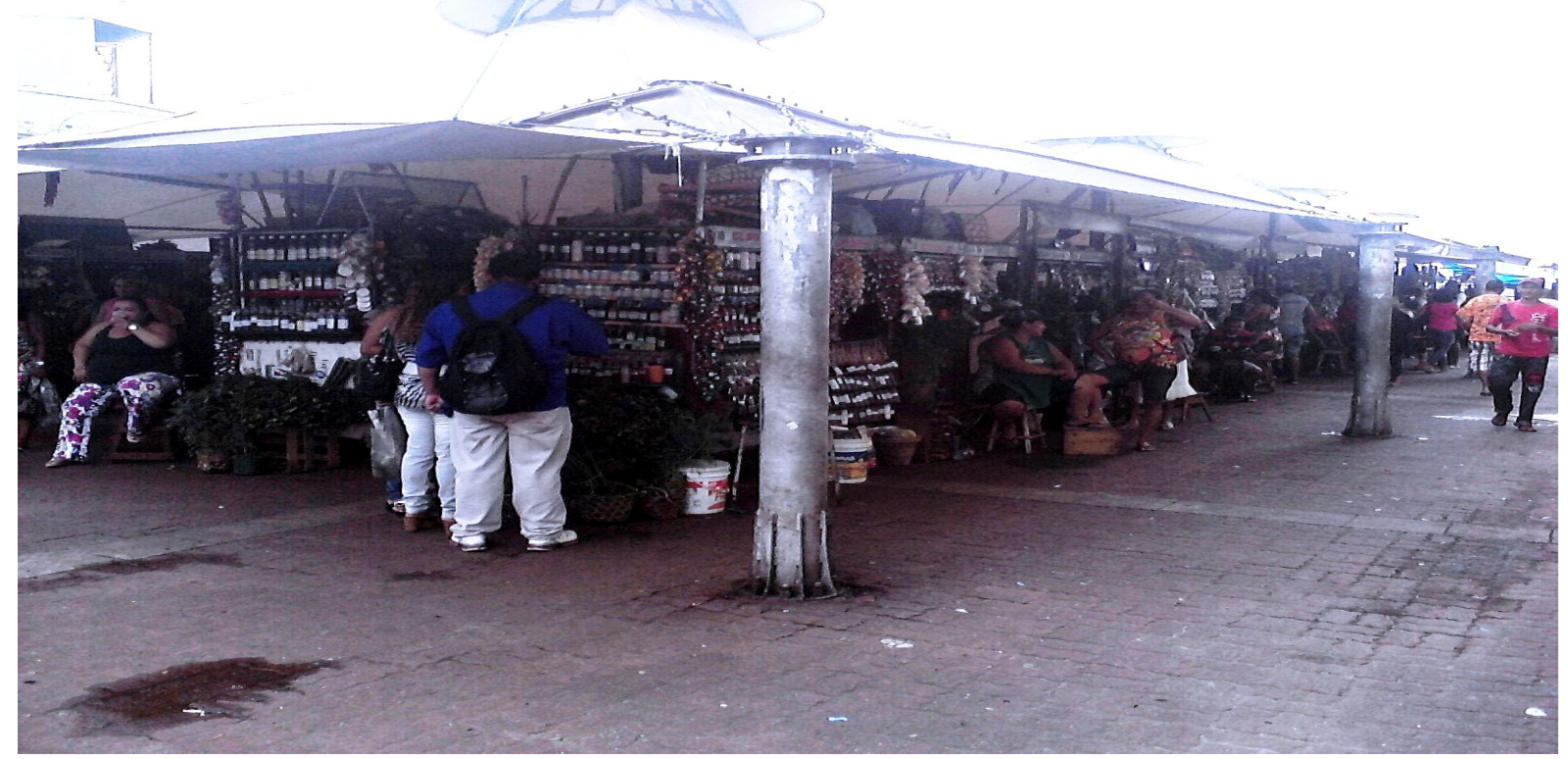

Fonte: Dados da pesquisa.

A segunda parte da investigação consistiu nas idas propriamente ditas ao setor de ervas da Feira do Ver-o-Peso. Destarte, quanto aos procedimentos destinados à coleta de dados adotou-se o survey que, segundo Pinsonneault e Kraemer (1993 apud FREITAS, 2000, p. 105):

[...] pode ser descrito como [um meio para] a obtenção de dados ou [de] informações sobre características, ações ou opiniões de um determinado grupo de pessoas, indicado como representante de uma população alvo, por meio de um instrumento $[\ldots]$.

De um modo geral, essa técnica consiste em incursões pontuais in loco para coletar evidências sobre o objeto de estudo, diferenciando-se da pesquisa de campo, que consiste numa presença mais prolongada do pesquisador na realidade investigada.

O survey resultou num total de quatro visitas ao setor dos(as) erveiros(as) da Feira do Ver-o-Peso, realizadas no período de janeiro a fevereiro de 2012, nos horários da manhã e da tarde. Com relação aos instrumentos utilizados na coleta de dados, optou-se pelo uso do diário de campo, da entrevista estruturada, da câmera fotográfica e do gravador. Ao todo foram entrevistadas 16 pessoas, das quais 10 são mulheres e seis são homens, com idades que variam entre 25 e 62 anos. Assim, exposta a metodologia e os instrumentos utilizados na pesquisa junto aos(às) erveiros(as), o material coletado em campo é apresentado e analisado a seguir. 


\section{Os(as) erveiros(as) como sujeitos detentores de conhecimentos tradicionais}

Partindo do pressuposto de que as pessoas ocupam papel central no processo de produção, processamento, armazenamento, recuperação e uso da informação, os(as) erveiros(as) da Feira do Ver-o-Peso são entendidos, nesta pesquisa, como fontes pessoais específicas de informação. Tal assertiva decorreu do survey realizado, em que se verificou que esses sujeitos são detentores de um complexo de informações de caráter prático (conhecimentos), referentes ao uso de plantas, cascas e raízes, ou seja, de produtos naturais aos quais são atribuídas certas propriedades curativas. Em seu conjunto, tais informações dizem respeito à classificação desses produtos obtidos na floresta ou nos quintais das habitações paraenses, bem como à procedência, às aplicações e aos métodos de preparo dos mesmos, formando um repertório de conhecimentos que se encontra armazenado apenas na memória.

Um esclarecimento importante a ser feito diz respeito ao entendimento de quem são os(as) erveiros(as) e sobre como os conhecimentos que possuem podem ser incluídos na categoria de tradicional. Os sujeitos em foco correspondem a homens e/ou a mulheres que trabalham no setor de ervas da Feira do Ver-o-Peso, comercializando produtos como plantas, cascas e raízes medicinais, cuja aplicação se destina desde doenças como o reumatismo a moléstias de caráter espiritual, como o mau-olhado ${ }^{6}$, por exemplo. Todavia, esses homens e mulheres não somente comercializam tais produtos como, também, possuem conhecimentos especializados para indicar e ensinar a forma adequada de preparo e de consumo dos mesmos. São esses aspectos que permitem classificá-los como sujeitos detentores de conhecimentos tradicionais. Assim, como explica Moreira (2007, p. 36):

Vale ressaltar que o que faz um grupo social ser identificado como tradicional não é a localidade onde se encontra, $[\ldots]$ enfim, não é o local que define quem elas são, mas sim seu modo de vida e as suas formas de estreitar relações com a diversidade biológica, em função de uma dependência que não precisa ser apenas com fins de subsistência, pode ser também material, econômica, cultural, religiosa, espiritual, etc.

Isso significa dizer que não é o fato dos(as) erveiros(as) não se encontrarem em áreas rurais, ribeirinhas, quilombolas ou em Terras Indígenas (TI) que os(as) exclui da condição de detentores de conhecimentos tradicionais. Ao contrário disso, representam um grupo de sujeitos que tem conseguido reproduzir esses conhecimentos na

6 De acordo com Cascudo ([20--?]), há uma crença milenar e universal nos malefícios que o mau-olhado pode causar, razão pela qual desde os tempos antigos e em diferentes culturas existem amuletos e fórmulas populares para combatê-lo, a exemplo do que ensinam os(as) erveiros(as) da Feira do Ver-o-Peso quanto ao uso de um pequeno ramo de arruda (Ruta graveolens L.) atrás da orelha. 
heterogeneidade do ambiente urbano. $E$, em que pese a existência de uma infraestrutura de saúde na capital paraense, tais conhecimentos ainda encontram formas de aplicação para tratar dos males do corpo e da alma entre as mais diferentes camadas da população local, apesar de todos os avanços da tecnologia médica e farmacêutica.

Logo, o que torna o grupo, aqui estudado, como sujeitos detentores de conhecimentos tradicionais é seu modo de viver, seus hábitos e, principalmente, suas histórias de vida (BARROS et al., 2007) associadas aos produtos que comercializam. Como se pôde levantar em campo, a maioria deles trabalha há décadas no setor de ervas da Feira do Ver-oPeso, tendo iniciado desde muito cedo o aprendizado sobre o uso e a comercialização de plantas, cascas e raízes medicinais. E em direção à identificação dos sujeitos contatados, no Quadro 1 que se apresenta, eles são caracterizados quanto à idade, ao tempo de trabalho no setor de ervas e ao local de procedência.

Quadro 1 - Caracterização dos(as) erveiros(as) da Feira do Ver-o-Peso

\begin{tabular}{cccc}
\hline Nome & Idade & $\begin{array}{c}\text { Tempo de trabalho no Ver-0- } \\
\text { Peso }\end{array}$ & $\begin{array}{c}\text { Local de } \\
\text { nascimento }\end{array}$ \\
\hline Beth Cheirosinha & 61 anos & 46 anos & Belém \\
D. Dudu & 54 anos & 45 anos & Felém \\
Valmira & 52 anos & 9 anos & Belém \\
Maria Helena & 59 anos & 30 anos & Belém \\
Miraci & 47 anos & Mais de 35 anos & Belém \\
Patrícia & 36 anos & 9 anos & Fortaleza \\
D. Gizeuda & 62 anos & 27 anos & Marituba \\
Maria Loura & 46 anos & 25 anos & Ponta de Pedra \\
Simony & 25 anos & 3 anos & Belém \\
Tia Coló & 58 anos & 33 anos & Araguapás/Goiás \\
César & 59 anos & 26 anos & Belém \\
Roni & 36 anos & 18 anos & Belém \\
Josinaldo & 42 anos & 32 anos & Belém \\
Marcelo & 37 anos & 25 anos & Belém \\
João & 49 anos & 26 anos & 25 anos \\
Tião & 45 anos & &
\end{tabular}

Fonte: Dados da pesquisa.

O tempo de trabalho mencionado no Quadro 1, acima, corresponde aos anos consecutivos de atividade nessa que é a maior feira livre da América Latina. Dentre os(as) erveiros(as), D. Beth Cheirosinha e Tia Coló são as mais antigas, pois estão no setor de ervas da Feira do Ver-o-Peso há exatos 46 e 33 anos, respectivamente. Valmira, Patrícia e Simony são as mais jovens, sendo que as duas primeiras trabalham nesse local há nove anos, cada, e, a última, há apenas três anos. Os(as) demais possuem entre 18 e 30 anos de atividade. Quanto à procedência, têm-se sujeitos de origem diversificada, embora a maioria seja constituída por paraenses. Entre os(as) erveiros(as), há aqueles que nasceram em Fortaleza (CE), como é o caso de Valmira e de D. Gizeuda, e Roni, que nasceu em Goiás. Os(as) demais são procedentes de município paraenses, como Belém, Marituba e Ponta de Pedras, este último localizado na Ilha do Marajó.

De acordo com os depoimentos coletados, a maioria declarou que acompanhava os pais no trabalho no Ver-o-Peso ainda na infância ou 
ajudando-os em casa a separar as plantas, as cascas e as raízes que lá seriam comercializadas, de forma que só muitos anos depois adotaram a atividade como única fonte de renda. Além dos pais, outros sujeitos foram importantes na socialização dos conhecimentos tradicionais, como tios(as) e/ou irmãos(ãs). Nesse processo de transferência de informações ${ }^{7}$ dos mais experientes para os neófitos, a oralidade e a observação (LÉVISTRAUSS, 2006) se mostraram essenciais no aprendizado dos(as) erveiros(as) da Feira do Ver-o-Peso. Simony e Valmira representam bem o primeiro exemplo, pois adquiriram o conhecimento que possuem ajudando os pais. Hoje, elas trabalham diariamente com a venda de plantas, cascas e raízes medicinais, rememorando:

Passei a vim tirando folgas da mamãe, né? Agora não. Agora já tô vindo diariamente (Simony, 25 anos, entrevista realizada em 01. 02. 2012).

Eu trabalhava com a minha mãe, desde pequena; eu trabalhava com a minha mãe em casa, tirando as ervas pra ela trazer pros banqueiros ${ }^{8}[. .$.$] (Valmira, 52$ anos, entrevista realizada em 30. 01. 2012).

Nessas falas é possível constatar que, ajudando os pais, elas

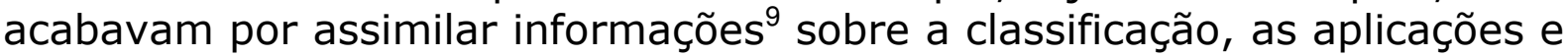
o modo de preparo de ervas, cascas e raízes medicinais, construindo o conhecimento que as levaram a ser donas de suas próprias barracas. Nota-se, assim, o papel do aprendizado informal e intergeracional ${ }^{10}$ na formação dos(as) erveiros(as) que atualmente trabalham nessa feira livre.

Mas, se para alguns e algumas o contato com o conhecimento sobre as plantas, as cascas e as raízes medicinais ocorreu de modo espontâneo no ambiente doméstico, a pesquisa revela que circunstâncias econômicas também constituem fatores de motivação para a aquisição das informações especializadas sobre trais produtos. Nessa direção, João se tornou erveiro quando ficou desempregado nos anos de 1980 . Na época, a atividade surgiu como uma oportunidade de geração de renda, sendo facilitada por parentes que já trabalhavam nessa feira livre e detinham conhecimentos tradicionais sobre esses produtos. Em depoimento, é possível observar a identificação de João com o ofício e o papel dos familiares na decisão de se tornar erveiro:

[...] trabalho aqui no setor das ervas desde 1986 [...] eu tava desempregado na época, aí eu tenho vários parentes que

7 Entende-se por transferência da informação, o processo amplo e complexo pelo qual as informações contidas em um determinado repositório são repassadas aos indivíduos em contextos sociais específicos (BARRETO, 1995). Assim, no caso dos(as) erveiros(as), as informações sobre os tipos, as aplicações e o modo de preparo mais adequado das plantas, cascas e raízes medicinais são recuperadas em seu repositório mental e transmitidas aos clientes de forma oral no ato da comercialização desses produtos.

8 Forma popular como denominam os proprietários de barracas no Ver-o-Peso.

9 A assimilação da informação deve ser entendida neste estudo dentro do que Barreto ([2002]) concebe como o processo pelo qual "estruturas de informação" são comunicadas nas relações sociais, alterando o estado cognitivo dos indivíduos e, gerando desse modo, um conhecimento novo.

10 Pantoja e Simonian (2010) mostram, inclusive, que algumas das pessoas que trabalham no setor de ervas da Feira do Ver-o-Peso são descendentes de mulheres que já desempenhavam esse mesmo ofício no século XIX. 
trabalham aqui, inclusive a minha mãe trabalhava aqui, trabalha já há vários anos. Aí surgiu a oportunidade deu vim trabalhar neste setor. Acabou que eu me acostumei e hoje eu não tenho coragem mais... eu... eu não penso na possibilidade de me ver exercendo uma outra função (João, 49 anos, entrevista realizada em 17. 02. 2012).

Embora a descoberta do ofício tenha emergido num contexto de crise, o fato é que, tal como os demais, João precisou adquirir informações específicas sobre as plantas, cascas e raízes medicinais para então exercer a atividade de erveiro.

Mesmo experimentando processos discriminatórios quanto aos conhecimentos que possuem, sendo por vezes acusados(as) de feiticeiros(as), os sujeitos entrevistados foram unânimes quanto à importância do ofício de erveiro(a) em suas vidas. Isto se deve, sobretudo, ao fato de sustentarem as famílias a partir dos saberes que detêm sobre o uso de plantas, raízes e de cascas medicinais. Neste ponto, Miraci, irmã de João, diz que:

O setor de ervas pra mim, ele representa a minha vida. Se eu não trabalhar aqui eu não sei fazer nada. Então pra mim é tudo, tudo! [...] É meu marido, é meu pai, é minha mãe [...] É tudo. É tudo. É tudo. É a minha vida o setor de ervas! (Miraci, 47 anos, entrevista realizada em 30. 01. 2012).

A exemplo do que outros(as) declararam, na fala de Miraci é possível perceber que é o complexo de informações que possuem sobre os produtos que comercializam no Ver-o-Peso que fundamenta o ofício que exercem. Contudo, apesar da compreensão do significado dos conhecimentos tradicionais em suas vidas, em campo também foi possível identificar o sentimento de incerteza quanto ao futuro.

Transmitido em contexto familiar e pelas relações de parentesco, os(as) erveiros(as) se mostraram preocupados(as) quanto à continuidade dos conhecimentos que possuem entre as gerações mais novas. Muitos são os fatores que sustentam tal incerteza, como: (1) a queda nas vendas em razão da concorrência com as casas especializadas em ervas que começam a se instalar em Belém; (2) as condições de higiene; e (3) a sensação de insegurança na Feira do Ver-o-Peso. Por outro lado, dadas as circunstâncias do mercado de trabalho atual, os(as) erveiros(as) têm preferido investir na educação dos filhos para melhorar as condições de vida. É nessa linha de pensamento que o depoimento de Miraci se revela emblemático:

Eu gostaria de poder ensinar pros meus filhos, mas como eu vejo que aqui no Ver-o-Peso é um setor bom de ganhar dinheiro, principalmente aqui no setor de ervas medicinais, mas há uma [...] uma discórdia. Uma desarmonia entre as pessoas, com os colegas, um querendo ser melhor do que os outros. 
Então eu não, eu não quero ver os meus filhos aqui no Ver-oPeso. Eu tenho dois filhos, um já está formado tem 26 anos, e infelizmente ele não pôde dar seguimento ao nosso trabalho, e tenho outro que ainda está com 12 anos, e que eu gostaria que ele fosse um médico farmacêutico [...] (Miraci, 47 anos, entrevista realizada em 30. 01. 2012).

Para além da competição por clientes e da busca dos(as) filhos(as) por formação superior, a questão da sustentabilidade também se impõe como um desafio à continuidade desse ofício tradicional na Feira do Ver-oPeso.

Desse modo, pelo que se levantou, poucos(as) são os(as) erveiros(as) que cultivam plantas medicinais em casa, pois a maioria não possui espaço suficiente em suas residências. Exceções de cultivadores são Simony (25 anos), João (49 anos) e Josinaldo (42 anos). Para os demais, a aquisição das ervas, das cascas e das raízes se dá por meio de terceiros, pois, de um modo geral, os produtos são originários de municípios próximos de Belém ou do interior do estado, que, trazidos para a capital, são encarecidos pelos intermediários.

Em que pesem as dificuldades, o que não se pode questionar é que as vivências desses sujeitos resultaram no acúmulo de informações sobre os produtos que comercializam, culminando num tipo de conhecimento que se aplica ao tratamento das doenças ligadas ao plano físico, psíquico e espiritual. Além das doenças, esse saber tradicional também é utilizado para produzir o bem-estar nos indivíduos melhorando as relações sexuais e/ou afetivas, profissionais e familiares (LIMA, 2008). Nestes casos, temse não apenas a indicação de plantas, cascas e raízes como, também, a indicação de defumadores, banhos e perfumes. Esses últimos inclusive aparecem registrados na Figura 2, formando o painel multicolorido que costuma ornamentar e caracterizar as barracas dos(as) erveiros(as) da Feira do Ver-o-Peso.

Figura 2 - O painel multicolorido de perfumes exposto na barraca da erveira Simony

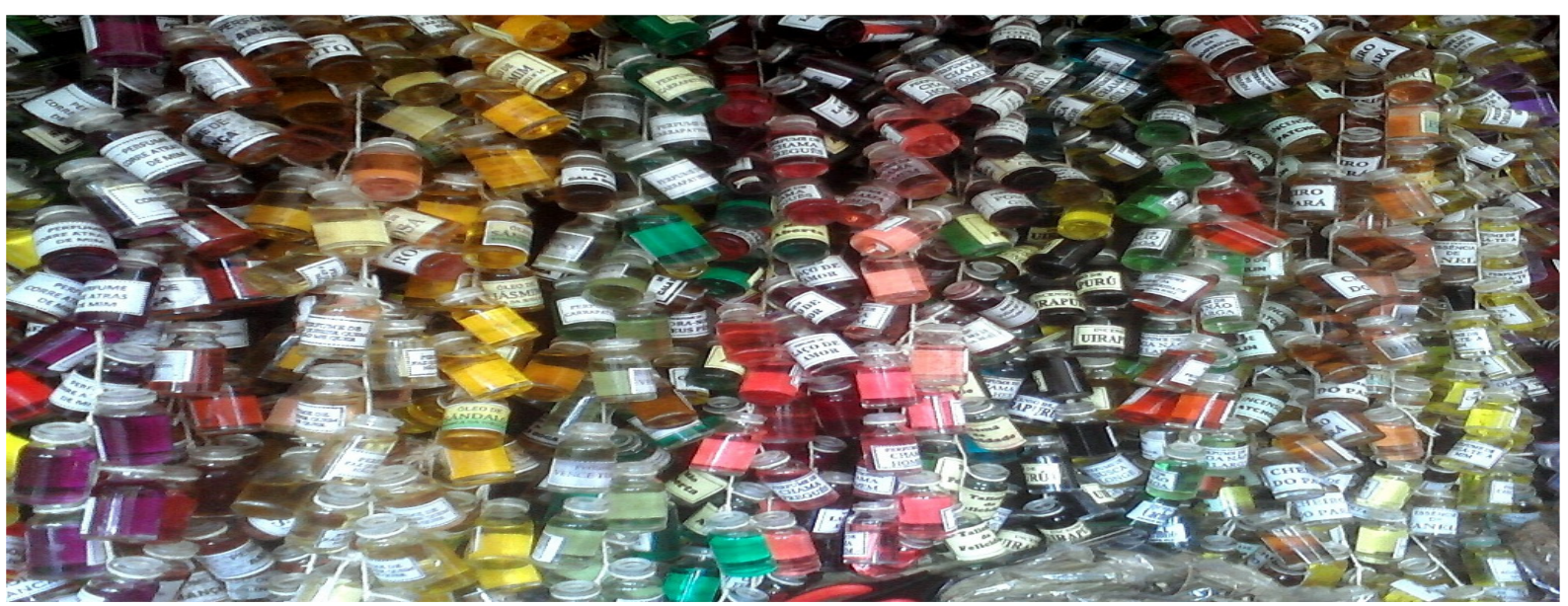

Fonte: Dados da pesquisa. 
De acordo com a necessidade dos clientes, os(as) erveiros(as) oferecem os chamados defumadores. Trata-se de compostos de ervas aromatizadas, que servem tanto como atrativos como meios de descarrego, entre outras funções. Segundo explicam, os(as) erveiros(as), o aroma dos defumadores exalado com a fumaça ajuda a afastar os maus espíritos e as energias negativas dos ambientes e, assim, a atrair os bons fluidos que são canalizados para as pessoas que os queimam. Tais produtos são abundantes e estão expostos nas barracas para venda do mesmo modo que os banhos, quer na forma de bastões cônicos, quer macerados.

Outros produtos muito procurados no setor de ervas da Feira do Ver-o-Peso são os fluídos, seja na forma de banhos ou de perfumes. Os banhos são preparados que utilizam plantas, raízes, cascas e, às vezes, animais, tendo as mesmas propriedades purificadoras ou atrativas dos defumadores. Por exemplo, para crianças com dificuldades de aprendizado, Tia Coló recomenda o "Banho dos estudantes". Assim como este, há outros que são preparados e colocados à venda com nomes que sugerem suas aplicações, a saber: banho atrativo; quebra inveja; chama freguês; mão aberta; abre as portas; e outros mais. Os perfumes, que aparecem na Figura 2, à semelhança dos banhos, também possuem propriedades purificadoras ou atrativas. Coloridos, eles resultam da combinação de chás obtidos de plantas, cascas e raízes que são misturados a perfumes conhecidos pela população, funcionando como uma espécie de "poção mágica". Os nomes que aparecem nos rótulos desses produtos já indicam os efeitos que se espera produzir sobre quem perfuma o corpo com eles: chega-te a mim; carrapatinho; vai e volta; encanto do boto; laço de amor; mil homens; corre atrás de mim; chama homem; chama dinheiro; e outros mais.

Perguntados(as) sobre os produtos mais procurados pelos clientes, os(as) erveiros(as) forneceram respostas diversas. Todavia, entre eles destacam-se os que são aplicados ao tratamento de doenças, alguns inclusive com efeitos já comprovados pela Ciência. São exemplos de produtos muito procurados pelos clientes os óleos medicinais, como o da andiroba (Caraba guianensis, Aubl.), da copaíba (Copaifera langsdorffii, Desf.) e do pequi (Caryocar brasiliense, Camb.); assim como o leite do amapá (Parahancornia amapa), o mel de abelha e as cascas obtidas de árvores amazônicas.

Os deslocamentos à Feira do Ver-o-Peso permitiram observar, sobretudo, que a oralidade possui papel preponderante na relação entre erveiros(as) e clientes. É, no processo comunicativo entre ambos, que ocorre a transferência da informação sobre as necessidades, as aplicações e o modo como cada produto deve ser utilizado para produzir o efeito desejado, seja para a cura de uma determinada doença ou para o reequilíbrio do indivíduo no plano espiritual. Nessa perspectiva, D. Beth Cheirosinha enfatiza que, além de gostar de possuir essas informações, gosta, também, de transmiti-la às pessoas que a procuram. Conforme explica: 
As pessoas que chegam aqui comigo [...] é, conta o problema dela aí eu já passo o remédio, já sei qual é o remédio certo, a erva que tem que tomar o chá, eu ensino o modo de usar porque essas ervas, veja bem, elas curam de verdade mas não pode ser feito com excesso, tem que ter o controle da erva, tem que saber tomar o chá, não pode tomar assim [...] adoidado não. Tem que tomar dentro do controle, igual como se você fosse tomar assim [...] um antibiótico que o médico passa, tem que ter a dosagem certa, a mesma coisa são as ervas. Não é porque é folha, dá no mato que também já vai tomar exagerado, tem que ter o controle pra fazer o chá, nisso eu sou profissional nessa parte, porque quando eu vendo eu ensino logo pro freguês o modo de usar, porque Deus o livre! Eu pergunto logo: você já sabe o modo de preparar? Você já sabe como fazer? Eu pergunto logo. Se ele disser "ah eu sei", mas se não souber eu tenho a satisfação de... aquele prazer de ensinar o modo de usar, como preparar o chá (D. Beth Cheirosinha, 61 anos, entrevista realizada em 30. 01. 2012, grifos nossos).

Na fala de D. Beth Cheirosinha, percebe-se o cuidado ao informar os clientes sobre o preparo e o uso "correto" das plantas, das cascas e das raízes que vende e, mais que isso, o alerta quanto ao uso abusivo desses produtos naturais. Isso significa dizer que, no ato da comercialização, ela e os(as) demais erveiros(as) precisam saber identificar o produto solicitado e buscar, em seu repositório cognitivo, as informações sobre as formas de uso e o preparo adequado de cada planta, casca ou raiz medicinal. Nesse momento, tem início uma operação mental de busca de informação que ocorre numa fração de tempo, e por meio da qual os(as) erveiros(as) fornecem as respostas às demandas dos clientes.

A respeito dos riscos aos quais os conhecimentos dos(as) erveiros(as) da Feira do Ver-o-Peso estão sujeitos(as), a pesquisa conseguiu apontar pelo menos aqueles tidos como críticos. O primeiro refere-se à possibilidade do esquecimento, a qual resulta da própria degeneração orgânica desses indivíduos, à medida que a idade avança no envelhecer. Ademais, se esse conhecimento não for transmitido a outros(as), como garantir a continuidade dele no futuro? Sobre o problema, D. Beth Cheirosinha consegue vislumbrar um caminho para garantir a transferência das informações especializadas que possuem e, assim, garantir sua continuidade:

Com certeza, não ficaria bem se alguém não desse a continuidade, tem que ter a continuidade, a gente tem que passar um pouco desse conhecimento pra alguém. É [...] eu passo para os filhos, tô passando agora aos domingos, que não tem aula, pras netas, sempre elas me acompanham por aqui, é muito importante esse conhecimento nosso [...] Deus 
me livre! Isso não pode morrer de maneira nenhuma. Eu não aceito isso. Tem pessoas que trabalham aqui na feira, que é só aquela pessoa, não traz um filho pra ajudar, não traz um... um... uma sobrinha, não traz ninguém pra passar o conhecimento. Aí, falo, vem a falecer, aí, não deixa pra ninguém. Tá errado! Tem que deixar pra alguém, dá continuidade (Beth Cheirosinha, 61 anos, entrevista realizada em 30. 01. 2012).

Todavia, em que pese o esforço de D. Beth Cheirosinha, resta saber se as expectativas de trabalho dos(as) filhos(as) e demais descendentes irão ser direcionadas para o ofício de erveiro(a) no futuro.

Uma segunda ameaça, por sua vez, corresponde à apropriação desse conhecimento sem levar em consideração as orientações normativas de acesso que protegem os direitos desses atores, o que pode resultar na exploração econômica sem a devida repartição de benefícios. Neste caso, o Estado, em sua estrutura legislativa, executiva e judiciária exerce papel preponderante na manutenção dos interesses das populações, das comunidades, dos grupos e dos indivíduos detentores de conhecimentos tradicionais. Também, deve ser incluída no enfrentamento dessa realidade, a organização sociopolítica desses atores, o que implica no acesso a informações sobre direitos e no reconhecimento dos saberes que detêm. Aspectos esses que se espera assistir num futuro próximo e que está a depender das articulações de todos os atores envolvidos nas questões que se relacionam à proteção dos conhecimentos tradicionais.

\section{Considerações finais}

Do ponto de vista teórico, verifica-se a importância desta pesquisa na possibilidade de sugerir um olhar interdisciplinar entre diferentes áreas sobre o tema dos conhecimentos tradicionais. Do ponto de vista prático, espera-se ter contribuído para despertar análises mais substanciais no campo da Ciência da Informação sobre um tipo de saber que possui particularidades históricas, sociais e culturais muito específicas. Isso porque os conhecimentos tradicionais são produzidos, transferidos e utilizados em certos contextos da vida cotidiana e, sobretudo, porque não se trata de algo ensinado/aprendido dentro de padrões formais de educação; mas de um legado que se transmite principalmente por meio da oralidade e da observação, ou seja, das interações sociais entre os(as) iniciados(as) e os neófitos(as) em suas práticas sóciocomunicativas, isto é, de intercambiamento de informações.

Ademais, tal como a literatura e a realidade observada na Feira do Ver-o-Peso estão a revelar, a problemática dos conhecimentos tradicionais impõe desafios à academia, ao Estado, ao mercado e aos próprios detentores desse saber. Desse modo, não só o Direito, a Antropologia, a Sociologia como outras áreas podem contribuir com estudos e análises sobre essa realidade como, também, a própria Ciência da Informação, 
precisamente por tomar como objeto de estudo a matéria-prima que estrutura as diferentes modalidades de conhecimento.

Assim, compreender os mecanismos pelos quais a informação é percebida e trabalhada na vida cotidiana dos detentores de conhecimentos tradicionais - como os(as) erveiros(as) da Feira do Ver-o-Peso - pode fornecer subsídios para se pensar em estratégias de preservação e de proteção desses saberes, transmitidos geração após geração.

Por fim, dada a complexidade do tema dos conhecimentos tradicionais, dos riscos que o envolvem e da necessidade de proteção, entende-se que se está diante de um problema no qual todas as questões relacionadas devem ser discutidas sob o enfoque multidisciplinar. Dessa maneira, as análises precisam ser amplas, envolvendo diferentes pontos de vista, seja do mercado, da academia, do Poder público e dos detentores, a fim de se chegar a um resultado satisfatório que contemple os interesses econômicos, a repartição dos benefícios e a valorização dos grupos e/ou dos indivíduos possuidores de conhecimentos tradicionais. Com efeito, protegê-los implica assegurar o direito de que esses sujeitos possam transmiti-los aos seus sucessores sem qualquer impedimento imposto pelo mercado na esfera das patentes, tal como objetiva a indústria farmacêutica e de cosméticos em relação às populações tradicionais de países subdesenvolvidos e em desenvolvimento.

\section{Referências}

APPOLINÁRIO, F. Dicionário de metodologia científica: um guia para a produção do conhecimento científico. São Paulo: Atlas, 2007.

ARAúJO, A. M. Medicina rústica. Rio de Janeiro: Ed. Nacional, 1959.

BARBOSA, E. J. S. Incubadora do conhecimento. Ciência da Informação, Brasília, DF, v. 26, n. 1, jan./abr. 1997. Disponível em: $<$ http://www.scielo.br/scielo.php?pid=S0100-

9651997000100013\&script=sci arttext $>$. Acesso em: 12 abr. 2012.

BARRETO, A. de A. A transferência de informação, o desenvolvimento tecnológico e a produção de conhecimento. INFORMARE: Caderno do Programa de Pós-Graduação em Ciência da Informação, Brasília, DF, v. 1, n. 2, p. 2-10, jul./dez. 1995.

BARRETO, A. de A. A transferência da informação para o conhecimento. [2002]. Não paginado. Disponível em: <http://aldoibct.bighost.com.br/A\%20transflnform.pdf>. Acesso em: 12 abr. 2012.

BARROS, A. de J. P. de; LEHFELD, N. de A. de S. Conhecimento científico. In: BARROS, A. de J. P. de; LEHFELD, N. de A. de S. Projeto de pesquisa: propostas metodológicas. Petrópolis: Vozes, 1990. p. 11-19.

BARROS, A. de J. P. de; LEHFELD, N. de A. de S. Natureza humana: conhecimento e saber. In: BARROS, A. de J. P. de; LEHFELD, N. de A. de 
S. Fundamentos de metodologia científica. 3. ed. São Paulo: Pearson Prentice Hall, 2007. p. 35-47.

BARROS, B. da S. et al. (Orgs.). Proteção aos conhecimentos tradicionais. Belém: Museu Paraense Emílio Goeldi: Centro Universitário do Pará, 2007.

BELKIN, N.; ROBERTSON, S. E. Information Science and the phenomenon of information. Journal of the American Society for Information Science, $\mathrm{p}$. 197-204 p., Jul./Aug. 1976.

BRAGA, G. M. Informação, Ciência da Informação: breves reflexões em três tempos. Ciência da Informação, Brasília, DF, v. 24, n. 1, n. 1, jan./abr. 1995. Disponível em: <http://www.brapci.ufpr.br/documento.php?dd0=0000000809\&dd1=2e865 > . Acesso em: 12 abr. 2012.

CASCUDO, C. Dicionário do folclore brasileiro. 10. ed. São Paulo: Ediouro, [20--?]. (Coleção Terra Brasilis).

CUNHA, M. B. da; CAVALCANTI, C. R. de O. Dicionário de biblioteconomia e arquivologia. Brasília, DF: Briquet de Lemos/Livros, 2008.

ECO, U. Como se faz uma tese. 21. ed.São Paulo: Perspectiva, 2007.

FREITAS, $H$. et al. Método de pesquisa survey. Revista de Administração, São Paulo, v. 35, n. 3, p. 105-112, jul./set. 2000. Disponível em: <www.rausp.usp.br/download.asp?file $=3503105$. pdf $>$. Acesso em: 12 fev. 2012.

KISHI, S. A. S. Conhecimento tradicional. In: BRASIL. Escola Superior do Ministério Público da União. Dicionário de direitos humanos. Brasília, DF: ESMPU, 2006. Disponível em: <http://www.esmpu.gov.br/dicionario/tikiindex.php?page=Conhecimento+tradicional $>$. Acesso em: 12 jan. 2012.

LARAIA, R. de B. Cultura:um conceito antropológico. 23. ed. Rio de Janeiro: Zahar, 2009.

LE COADIC, Y.-F. A ciência da informação. 2. ed. Brasília, DF: Briquet de Lemos, 2004.

LÉVI-STRAUSS, C. A ciência do concreto. In: LÉVI-STRAUSS, C. 0 pensamento selvagem. 6. ed. Campinas: Papirus, 2006. p. 15-49.

LIMA, M. D. de. Ver-o-Peso, patrimônio[s] e práticas sociais: uma abordagem etnográfica da feira mais famosa de Belém do Pará. 2008. 220 f. Dissertação (Mestrado em Antropologia)- Instituto de Filosofia e Ciências Humanas, Universidade Federal do Pará, Belém, 2008. Disponível em: $\quad<$ http://www.ppgcs.ufpa.br/arquivos/dissertacoes/dissertacaoTurma2006MariaLima.pdf>. Acesso em: 22 jan. 2012.

McGARRY, K. O contexto dinâmico da informação: uma análise introdutória. Brasília, DF: Briquet de Lemos/Livros, 1999. 
MENEZES, B. de. São Benedito da Praia: folclore do Ver-o-Peso. In: MENEZES, B. de. Obras completas. Belém: SECULT, 1993. (Série Lendo o Pará). p. 129-124.

MOREIRA, E. Conhecimento tradicional e a proteção. T\&C Amazônia, v. 5, n. 11, jun. 2007. Disponível em: <https://portal.fucapi.br/tec/imagens/revistas/005 rev011 conhecimento tradicional e a protecao.pdf $>$. Acesso em: 19 jul. 2010.

OLIVEIRA, V. R. de. Desmistificando a pesquisa científica. Belém: EDUFPA, 2008.

PANTOJA, A. L. N.; SIMONIAN, L. T. L. Economia familiar intergeracional a partir das mulheres negras da feira do Ver-o-Peso, Belém, Pa. In: SIMONIAN, L. T. L. (Org.). Belém do Pará: história, cultura e sociedade. Belém: Editora do NAEA, 2010. p. 558-577.

PINHEIRO, L. V. R.; LOUREIRO, J. M. M. Traçados e limites da Ciência da Informação. Ciência da Informação, Brasília, DF, v. 24, n. 1, 1995. Disponível em: <http://revista.ibict.br/index.php/ciinf/article/view/531/483>. Acesso em: 9 fev. 2012.

SANTILLI, J. A proteção jurídica aos conhecimentos tradicionais associados à biodiversidade. In: RIOS, A. V. V.; IRIGARAY, C. T. H. (Orgs.). O direito e o desenvolvimento sustentável: curso de direito ambiental. Brasília, DF: IEB, 2005. p. 71-84.

SANTOS, A. S. R. dos. Biodiversidade, bioprospecção, conhecimento tradicional e o futuro da vida. São Paulo, [20--?]. Disponível em: $<$ http://www.ccuec.unicamp.br/revista/infotec/artigos/silveira.html >. Acesso em: 16 fev. 2012.

SANTOS, L. G. dos. Saber tradicional x Saber científico. In: RICARDO, B.; RICARDO, F. (Org.). Povos Indígenas no Brasil 2001/2005. [S. I.]: Instituto Socioambiental, $2006 . \quad$ Disponível em: $<$ http://pib.socioambiental.org/files/file/PIB institucional/Saber tradicional saber cie ntifico.pdf $>$. Acesso em: 14 ago. 2010.

SARACEVIC, T. Interdisciplinary nature of information science. Ciência da Informação, Brasília, DF, v. 24, n. 1, 1995. Disponível em: <http://revista.ibict.br/index.php/ciinf/article/view/530/482>. Acesso em: 2 fev. 2012.

SOUZA, L. B. M.; CARVALHO, K. de. Disseminação da informação sobre plantas medicinais. In: ENCONTRO NACIONAL DE PESQUISA EM CIÊNCIA DA INFORMAÇÃO, 8., 2007, Salvador. Anais... Salvador: UFBA, 2007. Disponível em: <http://www.enancib.ppgci.ufba.br/artigos/GT3--168.pdf>. Acesso em: 11 jul. 2011.

SOUSA, L. B. de; BARROSO, M. G. T. Pesquisa etnográfica: evolução e contribuição para a enfermagem. Escola Anna Nery: Revista de Enfermagem, Rio de Janeiro, v. 12, n. 1, p. 150-155, mar. 2008. 
Disponível em: <http://www.scielo.br/pdf/ean/v12n1/v12n1a23.pdf>. Acesso em: 10 fev. 2012.

TEIXEIRA, G. Metodologia da pesquisa: tipos de conhecimentos. São Paulo, 2005.

WERSIG, G.; NEVELING, U. The phenomena of interest to information science. The Information Scientist, v. 9, n. 4, p. 127-140, 1975. 